\title{
La disgregación de una rica hacienda: el ocaso mercantil de los descendientes de Diego de Soria. ¿Un problema político?
}

\author{
The disintegration of a rich property: The mercantile decline of \\ Diego de Soria descendents. A political problem?
}

\author{
Betsabé Caunedo del Potro \\ UnIVERSIDAd AUTÓNOMA DE MADRID
}

\begin{abstract}
RESUMEN
Este trabajo trata de mostrar el rápido ocaso de una de las grandes familias burgalesas dedicadas al tráfico mercantil en el tránsito del siglo XV al XVI. Miembros de una tercera generación de mercaderes, tras superar serios problemas familiares e iniciar algunas operaciones comerciales, las abandonan viéndose envueltos en el «movimiento cumunero» que prendió en Castilla a principios del siglo XVI. Ello ocasionó, en parte, su ruina.
\end{abstract}

\section{PALABRAS CLAVE}

comercio burgalés; siglo XV - XVI; preparación y abandono de una carrera comercial; intervención en el conflicto «movimiento comunero»; ruina.

\section{ABSTRACT}

It intends to show the fast decline of one of the outstanding families devoted to trade in Burgos within transition from 15th to 16th centuries. Being 3rd generation descendants of merchants they face and get over several family disputes; they decide to start some business to give them up later, getting involved in the "Movimiento Comunero" that ocurred in Castille in early 16th century. Partly, that led to bankrupcy.

\section{KEYWORDS}

trade in Burgos; 15th century; start and cease of a business career; political problems; bankrupcy.

Son abundantes los nombres que conocemos de activos mercaderes que dedicados al comercio internacional operaron en Burgos en el floreciente último tercio del siglo XV. Del conjunto de todos ellos, hemos hecho sobresalir en diferentes ocasiones a Diego de Soria, ya que múltiples datos sobre sus empresas y negocios ${ }^{1}$,

\footnotetext{
${ }^{1}$ Ver mi trabajo «Los negocios de Diego de Soria, mercader burgalés», La Ciudad de Burgos, Actas del Congreso de Historia de Burgos, Madrid, 1985, pp. 163-172
} 
nos han permitido contemplar una hacienda notable, valiosa y diversificada que se había ido acumulando y gestionando a lo largo de 25 años de intenso trabajo, y que había granjeado a su poseedor uno de los primeros puestos en el mundo del gran comercio internacional castellano de finales del siglo XV. En esta ocasión, no es el lustre de su hacienda lo que nos impresiona, sino su rápida disgregación, y el también rápido abandono del comercio por parte de sus descendientes.

La continuidad de sus negocios preocuparía al mercader. Al no contar con hijos varones, había actuado con sumo cuidado en el momento de elegir un marido adecuado para sus hijas, y dos jóvenes prometedores desde el punto de vista de la dinámica mercantil: Alonso de Lerma y Alonso Pardo esperaban pacientemente el lento relevo generacional ${ }^{2}$, pareciendo probable que el papel del primogénito pasase a ser desempeñado por el joven Lerma, esposo de la hija mayor del mercader, Beatriz. En este caso, el venido de fuera, iba a tardar más en tomar el relevo de la «casa», de la empresa, apoyada entonces en una serie de principios rígidos y claramente continuistas. Pero no importaba, los dos jóvenes, ya con cierta formación mercantil —estaban completando su etapa de factores- fueron introducidos en los negocios de Diego de Soria al ser invertidos ciertos mrs. de las dotes en sus compañías ${ }^{3}$.

A estos candidatos pronto se les sumó un tercero, pues su hija Beatriz, sin tardar, le proporcionó el ansiado heredero varón. Su primer hijo, fue un varón que recibió el nombre de su abuelo, Diego, y a quien pronto se le denominaría Diego de Soria, el mozo, pues se le dio su nombre, Diego; y también su apellido: Soria, intentando traspasar al descendiente de igual nombre todos los atributos de su antecesor. Aunque no tuviese la misma importancia que en los linajes nobiliarios ${ }^{4}$, dado el carácter personalista de las compañías comerciales, estos detalles también eran relevantes, pues en el apellido se apoyaba un crédito, un buen hacer, un prestigio... y todo ello requería un reconocimiento más allá del ámbito de la comunidad local. Además, para afianzar el continuismo familiar, se dispone que el pequeño re-

\footnotetext{
${ }^{2}$ Ver comentarios sobre la política endogámica practicada por los mercaderes y detalles sobre estos enlaces en mi trabajo: «Comercio y hombres de negocios castellanos en tiempo de los Reyes Católicos. Técnicas y Aprendizaje», en, Comercio y hombres de negocios en Castilla y Europa en tiempos de Isabel la Católica, Congreso Internacional, celebrado en Burgos en Octubre de 2004, (actas en prensa), donde también ofrezco detalles sobre el carácter familiar de las empresas.

${ }^{3}$ Desde el primer momento, Alonso de Lerma puede considerarse «socio» de Diego de Soria, ya que $200.000 \mathrm{mrs}$, de la dote de Beatriz fueron invertidos por el propio Diego de Soria. A.R.CH. Valladolid, Pleitos Civiles, Ceballos Escalera, leg. 135, p.2. Y García Martínez de Lerma, padre del joven, colocó 200.000 mrs. de la dote correspondiente a su hijo en la compañía de los Covarrubias, de la que el joven Lerma era factor «... en pago de las dichas doscientas mill maravedis reçebio el dicho Alonso de Lerma de la dicha compañía de los dichos Covarrubias en Flandes, çien libras de gruesos y en Bretaña quinientas coronas ...» más adelante dirá «... fueronlas doscientas mil quel dicho Garçia Martínez de lerma le libró en los dichos Covarrubias e lo restante para en pago de lo quel dicho Alonso de Lerma avía estado en compañía de los dichos Covarrubias...» A.R.CH. Valladolid, Pleitos Civiles, Ceballos Escalera, leg. 135, cuadernillo cosido sin foliar.

${ }^{4}$ Ver un buen y reciente acercamiento al tema en QUINTANILLA RASO, M ${ }^{a} \mathrm{C}$. «Los grandes nobles», en El Mundo Social de Isabel la Católica, Madrid, 2004, 127-143 donde recoge una amplia bibliografía sobre el tema.
} 
sida en el domicilio de sus abuelos: Diego de Soria y Catalina de Maluenda, por le facer merçed $d^{5}$, cumpliendo la familia materna las primeras funciones de socialización del que se vislumbra como sucesor ${ }^{6}$. $Y$ así, durante un cierto tiempo las relaciones familiares fueron cordiales, sin sobresaltos, al cumplirse unas etapas mas o menos programadas. Los vástagos de sus hijas se incrementaban y numerosos Sorias, Lermas y Pardos, aseguraban una continuidad cuidadosamente diseñada por el gran mercader.

Sus yernos, Alonso de Lerma y Alonso Pardo, también despuntaban en el panorama mercantil burgalés. Lerma, era regidor -oficio que había heredado de su padre - y amparado por sus fuertes vinculaciones familiares era socio de importantes compañías en funcionamiento. Nada parecía que podía ensombrecer su futuro. Había sido bien preparado y tras su etapa de factor en el extranjero, en Flandes y Bretaña trabajando para la compañía de los Covarrubias, su carrera discurría por los cauces habituales, al igual que la del joven Pardo.

Pero diez, quince, veinte años pueden ser demasiados para «esperar». Pardo muere en el transcurso de los mismos, y a Lerma le resulta insuficiente su condición de socio, de segundón obediente, de acompañante de su poderoso suegro, siempre conforme con sus decisiones ${ }^{8}$. ¿Porqué no intentar aventuras personales?. La posibilidad de pérdidas o ganancias está siempre presente, se asume con mayor o menor conciencia, pero la tentativa de protagonismo, de autonomía, de poder prever y ejecutar negocios sin la mirada escudriñadora de los mayores, era fuerte y se impuso. Y quizá Alonso de Lerma se excedió. En 1494 parece incapaz de hacer frente a sus problemas financieros. En Florencia, sus acreedores le apremian para el pago de 1000 ducados que no tiene, por lo que se ve obligado a recurrir a su poderoso suegro, pensando que le concedería el préstamo sin avales. Así fue, Diego de Soria dio orden a su factor en Florencia, Alonso de Santo Domingo, de entregar a Lerma los 1000 ducados solicitados, cubriendo además la diferencia que se había generado en el cambio ${ }^{9}$.

\footnotetext{
5 «...que cuando nasçio el dicho Diego de Soria, el moço, contino estuvo en casa del dicho diego de Soria, su abuelo, e que cree que hera mas por le fazer a el merced que non por el serviçio que le façia... A.R.CH. Valladolid, Pleitos Civiles, Ceballos Escalera, leg. 135, p. 11.

${ }^{6}$ Sobre la formación y educación mercantil, ver mi trabajo, «La formación y educación del mercader», XVI Semana de Estudios Medievales, (actas en prensa).

7 Ver nota 3. Es sin embargo, mucho menos lo que sabemos del joven Pardo. Apenas la noticia de su matrimonio y prematura muerte en plena juventud.

${ }_{8}$ «... que con lo quel dicho Diego de Soria le dezia que le cabía de las dichas ganancias se contentava e contento e tuvo por contento el dicho Alonso de Lerma"... A.R.CH. Valladolid, Pleitos Civiles, Ceballos Escalera, leg. 135.

9 «... que puede aver agora ocho años mas o menos que estando el dicho Alonso de Lerma en necesidad y aviendo de cumplir çiertas debdas que devia en Florencia, rogo al dicho Diego de Soria que le emprestase mill ducados e que escribiese a Alonso de Santo Domingo, fator del dicho Diego de Soria, que estaba en Florencia, le diese los dichos mil ducados e quel dicho A. De Santo Domingo le emprestó mill ducados por mandado del dicho Diego de Soria e que dende a çierto tiempo el dicho Alonso de Lerma los pago al dicho Diego de Soria e el dicho Diego de Soria pago porel dicho A. De lerma lo que se perdió en el cambio de los mill ducados... A.R.CH. Valladolid, Pleitos Civiles, Ceballos Escalera, leg. 135, cuadernillo cosido sin foliar.
} 
Se detiene un golpe, pero Lerma no supera sus dificultades financieras. Un año después, invocando éstas, vuelve a acudir a su suegro con otra petición de dinero. En esta ocasión no recurre a un préstamo, pues piensa en otro medio, acaso más fácil, que por lo menos no precisa devolución. La legítima de su esposa se espera cuantiosa, y un «anticipo» en vida, quizá fuese suficiente para superar un mal momento, sobre todo si también se conseguía que fuese el experto y ya maduro mercader quien invirtiese ese dinero. Alonso de Lerma, esta vez acompañado por su esposa, pedirá «estos favores», y Diego de Soria, nuevamente solícito, los atendió. Asignará a Lerma la importante cantidad de $1.000 .000 \mathrm{mrs}$. en concepto de adelanto de la legítima de su esposa ${ }^{10}$ y recibe en su compañía a nombre de su yerno un importante "puesto» ${ }^{11}$. Todavía se mantenían buenas relaciones familiares que, sin embargo, pronto se enturbiarían.

Es probable que la carrera comercial de Lerma no se enderezase a pesar de estas importantes ayudas familiares. Quizá esperaba que fuesen mayores, menos interesadas, o que no se le tratase como a un acreedor más, o simplemente ansiaba mayores responsabilidades en el funcionamiento de las compañías, en los diferentes negocios; responsabilidades que no sólo no llegaban, sino que se veían cada vez más lejanas. Porque es también muy probable, que Diego de Soria, siempre exigente, a raíz de estas actuaciones «desastrosas» de su yerno, de sus negocios fallidos, de sus errores... lo apartase cada vez más de la toma de decisiones de los negocios familiares, fijándose en la siguiente generación, en su nieto, Diego, «el mozo», saltando la cadena normal y esperada de sucesión. El muchacho crecía a su imagen y semejanza, y se le estaba procurando una esmerada educación claramente diseñada por su abuelo, que se seguía a su entera satisfacción. Además él, aunque maduro, no era todavía un anciano. Podía esperar a que su nieto completase su formación y se encontrase en condiciones de tomar el relevo.

Él podía esperar, pero Alonso de Lerma estaba cansado de hacerlo, de obedecer... Acosado por la necesidad, ya no recurre el préstamo, tampoco a «adelantos» de su herencia. Los pasos siguientes fueron más osados y Lerma reclamó como impago parte de la dote de su esposa y los intereses devengados, pues se habían invertido, como dijimos, en una compañía comercial. No lo había hecho con

\footnotetext{
10 «... que puede agora aver siete años poco mas o menos quel dicho $A$. de Lerma tenia e tobo muchas necesidades e que a esta bes él y su mujer Beatriz de Soria fueron con mucha instancia a rogar al dicho Diego de Soria e a su muger que les quisiesen ayudar e socorrer en sus necesidades e que les quisieren dar algo con que pudiesen sostenerse e que ellos lo reçeberian en cuenta de su legítima e quel dicho Diego de Soria a su ruego, por las necesidades que tenian, le asygno un cuento de mrs. para en venta e pago de su legitima segund e como se contiene en la çedula que dello tiene presentado el dicho Alonso de Lerma...», A.R.CH. Valladolid, Pleitos Civiles, Ceballos Escalera, leg. 135, cuadernillo cosido, pregunta 16.

11 «...que al tiempo quel dicho Diego de Soria asyno el dicho cuento de mrs. como se contine en la pregunta e posición antes desta, asy mismo a ruego de los dicho A. De lerma e Beatriz de Soria, su muger, e por remedio de sus necesidades que tenia, el dicho Diego de Soria recibió en su compañía al dicho A. De Lerma...» A.R.CH. Valladolid, Pleitos Civiles, Ceballos Escalera, leg. 135, cuadernillo cosido, pregunta 17.
} 
anterioridad. Hasta entonces se había considerado bien pagado como Soria alegará una y otra vez, recordando que nada al respecto se había observado ante su grave enfermedad de 1496 y primera disposición testamentaria ${ }^{12}$, ni en las múltiples operaciones dinerarias que habían sido suscritas entre $\operatorname{ambos}^{13}$. No había reclamado nada con anterioridad. Pero en ese momento, quizá acuciado por la necesidad, mal aconsejado y con la prisa del heredero que ve perdida esa condición, Lerma cambia de actitud y promueve un largo pleito contra su suegro que agrió totalmente las relaciones familiares. Además a este primer pleito le seguirán otros como el que se mantuvo sobre la propiedad de 500 sacas de lana o sobre la solvencia de los fiadores presentados por Diego de Soria ${ }^{14}$, hasta culminar con el generado por la libertad de disponibilidad de bienes concedida a Diego de Soria por los Reyes Católicos, y que permitía desplazar a su hija Beatriz del mayorazgo principal y primar al hijo de ésta, Diego de Soria, el mozo, y a sus sobrinos Pedro Pardo y Juan Pardo Soria. Fue este desplazamiento la causa que algunos burgaleses ven para explicar la conducta de Lerma, y que el mismo admite no desmintiéndo$10^{15}$.

Este pleito determinaría que Diego de Soria, el mozo, el elegido para ser el privilegiado heredero de su abuelo, tuviese que conformarse con el quinto de sus bienes, los de libre disposición, constituidos en mayorazgo.

Llegar a esa solución había sido difícil y probablemente dolorosa. Como a buen mercader, calculador, le mortificaría el problema del reparto de su cuantiosa herencia, pues todo reparto conducía inexorablemente a la disgregación, mal que corroía a cualquier herencia. Ocasionaba una mengua muy importante del capital acumulado y dificultaba, sin lugar a dudas, futuras inversiones. Sus descendientes tendrían que conformarse con ser socios «modestos» de algunas compañías, escapándoseles la condición de principal. Para evitar esa peligrosa disgregación, Diego de Soria, pudo recurrir al mismo procedimiento que la alta nobleza, la institución

12 «... sy cuando el dicho Diego de Soria estovo malo a la muerte puede aver seys o syete años, el dicho Alonso de Lerma e su muger estovieron presentes al tiempo quel dicho Diego de Soria hordenó su testamento ni el dicho A. De Lerma ge lo acordo ni dixo...» A.R.CH. Valladolid, Pleitos Civiles, Ceballos Escalera, leg. 135, cuadernillo, pregunta 22.

${ }^{13}$ Diego de Soria en un segundo interrogatorio que presenta para que se interrogue a su yerno, alude a las múltiples cuentas que había suscrito con él, las distintas ocasiones en que le había abonado intereses por sus puestos en la compañía, ocasiones propicias para que Lerma le hubiese reclamado esta deuda. Nunca lo había hecho. Soria también insiste en que su hija se consideraba pagada, y le acusa claramente de querer postergar el asunto hasta después de su desaparición «...quel dicho Alonso de Lerma viendo quel dicho Diego de Soria fera fonbre viejo tobo encobierta la dicha çedula para la manifestar después de sus dias e en tiempo que no pudiese descobrirse la symulaçion e burla que en ella ay...» A.R.CH. Valladolid, Pleitos Civiles, Ceballos Escalera, leg. 135, cuadernillo cosido sin foliar

${ }^{14} \mathrm{Me}$ ha permitido el artículo «Acerca de la riqueza de los mercaderes burgaleses. Aproximación a su nivel de vida», En la España Medieval, 16,1993,97-118

15 «...a dicho el dicho A. De Lerma a muchas personas que sy Diego de Soria hiziera el mayorazgo a su muger de $A$. De Lerma como lo hazia a su hijo que nunca pidiera lo que agora pide ni se pusiera en ello... »Se trata de la pregunta 23 del interrogatorio anteriormente citado, A.R. CH. Valladolid, Pleitos civiles, Cevallos Escalera, leg. 135. Alonso de Lerma no desmiente el comentario, sólo responderá a la pregunta diciendo «... que no se acuerda de averlo dicho:...». 
de un mayorazgo. Vinculando propiedades, podía beneficiar a un heredero. El 14 de febrero de 1502 Los Reyes Católicos le habían concedido el ansiado privilegio ${ }^{16}$ que lo dignificaba socialmente y protegía su fortuna. Pero también le exigía elegir un heredero. Y Diego de Soria, pensó en su nieto primogénito, aquel que desde su nacimiento había compartido sus días, su morada.... en el que había volcado toda su ternura, y al que, además, se le estaba proporcionando una educación mercantil que presagiaba éxitos en el mercado internacional.

Empezaría tras esta decisión, un largo camino de diferencias y pleitos, que llegaron hasta la Chancillería de Valladolid ${ }^{17}$, que sin duda, amargaron los últimos años de la vida del mercader y que se complicaron aún más, cuando su hija Beatriz alegó que el nuevo privilegio real concedido en Burgos el 10 de Febrero de 1497, que concedía al mercader la casi libre disposición de su cuantiosa herencia $^{18}$, dañaba los intereses de su legítima ${ }^{19}$. Los monarcas tuvieron que modificar su privilegio, indicándole a Diego de Soria y a su esposa que mantenían el anteriormente concedido pero siempre que se guardasen las leyes del reino con respecto a la legítima que debía corresponder a su hija Beatriz. A la vez, ordenan que se le comunicase rápidamente esta decisión al mercader para que dispusiese de su hacienda teniéndolo en cuenta ${ }^{20}$. Y así, éste tuvo que modificar su decisión y atenerse escrupulosamente a las leyes del reino. La reclamación de su hija Beatriz supuso que sólo dispusiera para favorecer a sus nietos del quinto y tercio de sus bienes. Con ellos constituyó tres mayorazgos: uno sobre el quinto, a favor de su nieto primogénito, y dos sobre el tercio, a favor de sus nietos Pedro de Soria y Juan Pardo Soria, los hijos de Leonor, que vieron integrarse en sus mayorazgos, la

${ }^{16}$ A.G.S. Consejo Real, leg. 15

${ }^{17}$ A los que ya hemos hecho relación en las notas 14 y 15

18 «... vos damos liçençia, poder e facultad para que agora e de aquí adelante en vuestra vida o por vuestro testamento e postrimera voluntad, cada e quando quisieredes e por bien tovieredes, podades faser e fagades un mayorazgo o dos de qualquier vuestro bienes muebles e raíces e somobientes, oro e plata, joyas e dineros, heredamientos e maravedis de juro e terçias e tributos de çenso asy de dineros como de pan e patronazgos e de otros qualesquier vuestros bienes que avedes e tenedes e ovieredes e tovieredes de aquí adelante, de qualquier parte e partes dellos que vos quisieredes e por bien tovieredes a Diego de Soria, vuestro nieto mayor, fijo de Alonso Lerma e Beatriz de Soria, vuestra fija o en Pedro de Soria, fijo de Alonso Pardo e de Leonor de Soria, vuestra fija, defuntos, y en otros qualesquier vuestros nietos pues no teneis fijo varon y en sus dezendientes de legitimo matrimonio nacidos e non en los transversales o en otras qualesquier personas, vuestros parientes o estranos de qualquier calidad y estado que sea con qualesquier vinculos e firmeças e fuerças e sumesiones e sostetaçiones, modos e reparos e según e por la forma e manera que por vosotros fuere hordenado e mandado y establecido..." A.R.CH. Valladolid, Pleitos Civiles, Fenecidos, Pérez Alonso, C $908-5$.

19 «...e agora por parte de la dicha Beatriz de Soria, muger de Alonso Lerma, vesino e regidor de la çibdad de Burgos, fue suplicado de la dicha nuestra carta, deziendo ser agravio e perjuyçio por muchas razones que ante nos dixo e alego, especialmente diciendo que la dicha liçençia e facultad no se devia dar al dicho Diego de Soria ni a la dicha Catalina de Maluenda, su muger, para faser dicho mayorazgo o mayorazgos, legatos, mandas e donaciones entre bibos en su perjuyçio e de su legitima...» A.R.CH. Valladolid, Pleitos Civiles, Fenecidos, Pérez Alonso, C 908 - 5.

${ }^{20}$ «... mandamos que le sea notificado en tiempo que puedan disponer de sus bienes según en la forma en esta nuestra carta conthenido e que en otra manera, esta nuestra declaración e limitación no tenga ninguna fuerça ni hefeto alguno...» A.R.CH. Valladolid, Pleitos Civiles, Fenecidos, Pérez Alonso, C 908 -5 . 
herencia de sus padres, ya fallecidos ${ }^{21}$.La legítima reclamada por Beatriz se le respetó, y con ella se instituyó un cuarto mayorazgo ${ }^{22}$, en el que también se observa la clara predisposición del mercader por favorecer a su nieto primogénito. Está vinculando bienes muebles, una serie de rentas y censos, y también $2.000 .000 \mathrm{mrs}$. a su hija, pero pensando en el hijo de ésta. A él le correspondería a la postre, pues el joven Diego sería también el primer beneficiario del mayorazgo de su madre ${ }^{23}$. Ello no daña la legítima de Beatriz —-Diego de Soria lo repite insistentemente- ya que el mayorazgo se constituye precisamente con parte de esos bienes ${ }^{24}$. Además, se perpetuaba su memoria, la de su primogénito, y se disponía libremente de la parte no vinculada para dotar al resto de sus nietos ${ }^{25}$.

En la redacción de este documento de mayorazgo se observa también un especial cariño hacia su nieto primogénito, una gran confianza en su buen hacer ${ }^{26}$, a la vez que una tremenda desconfianza y abierta hostilidad hacia su yerno: Alonso de Lerma. El mayorazgo de Beatriz lo constituían propiedades rurales en las proximidades de Burgos, en Quintanilla de Somuño, Celada del Camino, Villatoro y Villaverde de Peñahorada, tierras en la propia ciudad de Burgos, todas arrendadas por el mercader y que le generaban en total 117 fanegas y once cargas de pan, y que se valoraron en 247.000 mrs. , a las que se le unían seis censos en los mismos lugares que le suponían la entrega de 16,5 fanegas, cuatro cargas de pan y algunas gallinas, y que se valoraron en 74.000 mrs., más una cantidad en dinero, 2.000.000 mrs. destinados a ser invertidos en bienes raízes o rentas ${ }^{27}$. Pero se or-

${ }^{21}$ Estos tres mayorazgos se conservan insertos en el pleito de Chancillería que sigue Pedro Pardo con el concejo de Pampliega sobre unas rentas de pan de censo, heredadas precisamente de su abuelo, y vinculadas por éste en el mayorazgo con el que le benefició. A.R.CH. Valladolid, Pleitos Civiles, Fenecidos, Pérez Alonso, C 908 - 5.

22 Este cuarto mayorazgo también se inserta en el pleito comentado en la nota anterior.

${ }^{23}$ «... e quede enteramente e para syenpre por mayorazgo en esta manera, en la dicha Beatriz de Soria, nuestra hija, goze en byda de los dichos bienes que asi dexamos por mayorazgo e de los frutos e rentas de ellos, e que después de sus dias aya y herede el dicho mayorazgo Diego de Soria, regidor de la çibdad de Burgos, fijo legitimo mayor de la dicha Beatris de Soria e de Alonso de Lerma, regidor de Burgos, su marido, e sus descendientes barones legítimos e de legitimo matrimonio nacidos..." A.R.CH. Valladolid, Pleitos Civiles, Fenecidos, Pérez Alonso, C $908-5$.

24 «... Otrosy asignamos e damos para después de nuestros dias a la dicha Beatriz de Soria, nuestra fija legítima, en su parte e legitima que de los dichos nuestros vienes le pertenecen e pueden pertenecer, sacado el terçio e quinto de que hemos dispuesto...» A.R.CH. Valladolid, Pleitos Civiles, Fenecidos, Pérez Alonso, C $908-5$.

${ }^{25}$ Dice que ella «... debe de aver por bien, porque queda su memoria juntamente con la nuestra perpetuada en el dicho Diego de Soria, su hijo, nuestro nieto...»; «... no entendemos que agraviamos la legitima de la dicha Beatriz de Soria, nuestra hija, pues que por las facultades que de suso se contienen tenemos e tiene poder e facultad para vincular toda su legitima e dexarla por mayorazgo, la qual nosotros no vinculamos salvo solamente los bienes rayses suso dichos e los dichos dos quentos de maravedis e lo restante de la dicha legitima lo dexamos libre para que pueda dotar sus fijos e asignar e dar su legitima a los otros sus hijos e fijas...» A.R.CH. Valladolid, Pleitos Civiles, Fenecidos, Pérez Alonso, C 908 - 5.

${ }^{26}$ Refiriéndose a él, su abuelo dirá «... e lo merece mejor que ninguno de los otros sus hijos...» Y más adelante confirmará su buen hacer «...él terna derecho e razon para procurar como los dichos dos quentos se empleen en vienes raíces e rentas para el dicho mayorazgo e no se gasten ni consuman en su perjuyçio..." "posibilidad si no se hubiese invertido con anterioridad el dinero vinculado al mayorazgo. A.R.CH. Valladolid, Pleitos Civiles, Fenecidos, Pérez Alonso, C 908-5.

${ }^{27}$ Comienza la relación de las propiedades del mayorazgo «... primeramente ponemos e incorporamos en este nuestro mayorazgo las tierras que tenemos arrendadas en Quintanilla de Somuño a Juan 
denaba que de ninguna manera pudiese Beatriz disponer de ese dinero, ya que ello facilitaría que el esposo de ésta, Alonso de Lerma, lo pudiese utilizar, gastar y a juicio del testador, malgastar y perder. «... que no ayan de entrar ni entren en poder de la dicha Beatriz de Soria, nuestra hija, porque Alonso de Lerma, su marido, no aya lugar de meter las manos en ellos, e los gastar e destroyr como fa fecho con otra mucha façienda... » idea que repetirá varias veces en el documento ${ }^{28}$.

Con los 2.000 .000 mrs. se constituía un depósito, que cobijado en el monasterio de San Juan, claramente se inmovilizaba. No se esperaba de él la más mínima rentabilidad hasta que se pudiese invertir en tierras o rentas. Pero hasta que llegara ese momento, el dinero, la no desdeñable cantidad de 2.000 .000 mrs., perdía rápidamente su valor, algo que en ese momento parecía no importar. Suponía un cambio de actitud significativo, explicable por la desconfianza del mercader hacia su yerno, pero era una actitud que se consolidaba, ya que tampoco se contemplaba la posibilidad de que el joven Soria, - del que en absoluto se desconfiaba- pudiese invertirlos cuando llegasen a sus manos. La decisión era firme, y aunque en la misma estuviese presente una amarga experiencia personal -las dolorosas consecuencias derivadas de la inversión de parte de la dote de Beatriz en la compañía de su padre- también significaba un cambio de mentalidad ${ }^{29}$. La inversión en bienes raíces y rentas, además de ser más segura, resultaría a la larga, menos traumática.

Con la constitución de los cuatro mayorazgos, Septiembre de 1504, parecía que el reparto patrimonial podía quedar zanjado. Las disposiciones y cláusulas de trasmisión —comunes a este tipo de documentos-contemplan todos los posibles supuestos por muy remotos que se vislumbrasen. Sin embargo, Diego de Soria, obsesionado por el problema del reparto, introduciría nuevos retoques. Apenas unos meses después, en junio de 1505, sintiéndose muy enfermo - su enfermedad de gota se había agravado hasta impedirle firmar ${ }^{30}$ - dicta una carta de codicilo que modificaba levemente disposiciones anteriores. Pequeños ajustes tras múltiples cálculos y números para que los mayorazgos se ajustasen realmente al

Miguel e A. De los Barrios e a Fernando de Lomas e a Juan de Burgos, vesinos del dicho lugar, e nos dan de renta treynta fanegas de pan de medida mayor, según pareé por nuestro libro de compras, que las tasamos en quarenta e çinco mill maravedí...:`Continúa después la relación «... e después de los bienes susodichos e declarados... dos quentos de maravedis, los quales dichos dos quentos de maravedis, queremos e hordenamos que la dicha Beatriz de Soria, nuestra fija, aya y herede por mayorazgo...” A.R.CH. Valladolid, Pleitos Civiles, Fenecidos, Pérez Alonso, C $908-5$.

${ }^{28}$ Dirá más adelante «... que los dichos dos quentos que asy dexamos para el dicho mayorazgo no se henaxenen, gasten ni destruyan ni desypen ni bengan a poder del dicho Alonso de lerma, su marido, que lo gastarya e desyparya como dicho es ...» A.R.CH. Valladolid, Pleitos Civiles, Fenecidos, Pérez Alonso, C $908-5$.

${ }_{29}$ Diferentes ejemplos de este cambio de mentalidad los encontramos en CAUNEDO DEL POTRO, B., y SÁNCHEZ MARTÍN, M., «Menores y huérfanos en la comunidad castellana de Brujas. Una primera aproximación a su estudio", Espacio, Tiempo y Forma, 1988, pp. 39-60. Prácticamente todos los tutores de los huérfanos de mercaderes asentados en Brujas tratan de conservar la hacienda no de incrementarla a pesar, incluso, de las recomendaciones de los progenitores difuntos.

${ }_{30}$ »estoy agravado de my enfermedad de gota e no puedo firmar «... lo especifica para autorizar a su esposa a que firme por él. A.R.CH. Valladolid, Pleitos Civiles,Fenecidos, Perez Alonso, C 908-5. 
tercio y quinto de sus bienes. Así traslada $20.000 \mathrm{mrs}$. de renta sobre las alcabalas del vino de la ciudad de Burgos del mayorazgo de su nieto Pedro al de su nieto Diego. $Y$ también vuelve a mostrarse sumamente respetuoso con los bienes de su esposa, renunciando a la posibilidad de intervenir o vigilar su última voluntad. Ella podría disponer como quisiere de sus bienes e hacienda ${ }^{31}$.Parece un último reconocimiento al papel que su matrimonio le había supuesto. Catalina de Maluenda había sido un excelente puente en su acceso a la oligarquía burgalesa.

En Mazuelo, aquejado de su enfermedad de gota que se había agravado, había efectuado estos pequeños retoques. Cuando levemente mejorado vuelve a Burgos, recibe con alegría una modificación de las leyes generales del reino con respecto a los repartos hereditarios que permitían incrementar - aunque tampoco de un modo sustancial- la mejoría de su nieto Diego de Soria, el mozo. El mayorazgo constituido a su favor era sobre el quinto de sus bienes, no podía ser más, ya que Beatriz, madre del joven, vivía. Ahora, independientemente de que los padres viviesen o no, los nietos podían ser mejorados por sus abuelos en el tercio y quinto de su patrimonio. De ese modo, los tres jóvenes Soria, Diego, Pedro y Juan Pardo de Soria, los tres, se beneficiarían con el tercio y quinto de los bienes de su abuelo, vinculándolos vía mayorazgo ${ }^{32}$. Ello supuso nuevos retoques en el reparto, y dos nuevos codicilos. En uno, se amplía el mayorazgo de Diego con propiedades en Mazuela: una viña de moscatel, una guindalera y una huerta grande, -aunque prácticamente todas las propiedades de Mazuela se había dispuesto pasasen a Pedro de Soria en el mayorazgo que lleva precisamente ese nombre: Mazuela - heredades, casas y censos sobre algunos vecinos de Torrepadierna. Y en el otro, dictado en Burgos el 14 de julio de 1507, ya totalmente en las puertas de la muerte, ese mismo mayorazgo se amplía con unas casas en Burgos, barrio de San Esteban, con 30 cargas de pan de censo sobre el concejo de Posada de Socastro, lo que supuso un incremento de $260.000 \mathrm{mrs}$. en su valor. A la vez, se confirma a Pedro de Soria, una espléndida heredad y casa en Villagutierre, vinculadas también a su mayorazgo, y se matizan algunas cláusulas generales sobre la trasmi-

\footnotetext{
31 „...que la dicha Catalina de Maluenda, my muger, pueda faser de la su azienda lo que quisiere e testar e faser testamento como le plugiere»... declara e manda que «lo pueda faser no enbargante la facultad que tendo del rey e de la reyna nuestros señores para faser el dicho mayorazgo o mayorazgos... e pueda menorar a quien quisiere en lo que quisiere...»A.R.CH. Valladolid, Pleitos Civiles, Fenecidos, Pérez Alonso, C 908-5

32 «... deçimos que por quanto nos, los suso dichos, avíamos fecho majorya del terçio de nuestros bienes a Pedro de Soria e a Juan Pardo de Soria, nuestros nietos, fijos de Alonso Pardo e de Leonor de Soria, nuestra fija, ya defuntos, e avíamos mejorado del quinto de todos nuestros bienes a Diego de Soria, regidor, nuestro nieto, fijo de Alonso de Lerma e Beatriz de Soria, su muger, nuestra hija, lo qual feçimos por que fuimos informados que no podíamos mejorar al dicho Diego de Soria, nuestro nieto, en balor de mas del dicho quinto por ser biba Beatriz de Soria, nuestra fija,su madre, e agora vista la ley nuevamente fecha por la reyna, nuestra señora, en que dispone que los abuelos puedan mejorar a los sus nietos en el terçio e quinto de sus bienes no ostante que los padres de los tales nietos sean vibos, agora usando del remedio de la dicha lay, declaramos nuestra voluntad e mandamos e mejoramos a Pedro de Soria e a Diego de Soria, regidor, e a Juan Pardo de Soria, nuestros nietos e todos tres juntamente en el terçio e quinto de todos nuestros bienes...» A.R.CH. Valladolid, Pleitos Civiles, Fenecidos, Pérez Alonso, C 908-5
} 
sión. Así, qué hacer ante la posibilidad que los mayorazgos pudiesen ser heredados por dos hermanos mellizos o gemelos o por un demente ${ }^{33}$.Insiste también el mercader en cómo solucionar el problema que se suscitaría si los mayorazgos constituidos excediesen, a pesar de todos los cálculos y reajustes, al tercio e quinto de los bienes de libre disposición. Las propiedades vinculadas, no deben en ningún modo alterarse, menos reducirse, por lo que Pedro de Soria y Juan Pardo de Soria, podrían aplicar a los suyos hasta completar ese tercio y quinto, la legítima que les correspondiese, en el futuro, de la herencia de sus abuelos ${ }^{34}$. Y Diego de Soria, el mozo, lo completaría con la legítima de su madre, añadiéndole, además, su abuelo, 200.00 mrs. para poder cubrirlo. Realmente el mercader se sentía temeroso. Sus cálculos podían haber resultado excesivos ${ }^{35}$.

Muestran también estos últimos retoques, además de la obsesiva preocupación por la no desintegración de su hacienda, la enorme capacidad de trabajo y habilidad negociadora del mercader. Gravemente enfermo, apesadumbrado por las rivalidades familiares, todavía está atento a la rentabilidad de sus inversiones. Este objetivo, que siempre le había acompañado, vemos que se traduce en estos últimos momentos en la adquisición de 30 cargas de pan de censo sobre el concejo de Posada de Sotocastro. Estas cargas de pan se las cambió a A. Muñoz de Castañeda, por 10 cargas de pan de censo en la villa de Miro y un par de casas en esta misma localidad ${ }^{36}$. Realmente prefería que hubiese un único responsable del pago; en este caso el concejo. Simplificaba gestiones de cobro, ahorraba tiempo, y por lo tanto, dinero. Suponía también una mayor garantía en el cobro, y agrupaba propiedades, siempre objetivo mas deseable que la dispersión y disgregación.

\footnotetext{
${ }^{33}$ El estado de demencia inhabilitaría para la posesión de los mayorazgos, pero no a los herederos del posible demente. En el caso de mellizos o gemelos, el primero en nacer sería al que le correspondiese el mayorazgo, y ante la imposibilidad de determinar el orden en el nacimiento, sería el poseedor del mayorazgo el que escogiese entre los dos hermanos a su sucesor. A.R.CH. Valladolid, Pleitos Civiles, Fenecidos, Pérez Alonso, C 908-5

34 «... mandamos que los dichos Pedro de Soria e Juan Pardo de Sorya, nuestros nietos, todavía ayan e gozen de los dichos bienes de los dichos mayorazgos que a ellos mandamos syn desminuçion alguna e que lo que asi les ezediere del dicho terçio e quinto que ayan de dexar de su parte, que lo ayan por en quenta de su legítima que de nos e de qualquier de nos le perteneciere e quede tanbyen vinculado con los mismos vinculos e sumisiones e costetuçiones para syenpre jamas..." A.R.CH. Valladolid, Pleitos Civiles, Fenecidos, Pérez Alonso, C 908-5

35 «...Otrosy, dixeron e declararon los dichos Diego de Sorya e Catalina de Maluenda, su muger, que sy caso fuere que los bienes mandados por via de mayorazgo al dicho Diego de Soria, regidor, subieren e excedieren del terçio e quinto e no cupieren e no bastaren para lo que asy les es mandado en el dicho mayorazgo, que del monte de todos sus vienes que dellos quedaren se saquen doscientos mill maravedis e se le den al dicho Diego de Soria para ayuda de cumplir lo que faltare quedando todavía lo que suso dicho e mandado es en el su fuerça e vigor, lo qual todo dixeron que declaraban e mandaban e declararon e mandaron por via de codezilo...» A.R.CH. Valldolid, Pleitos Civiles,, Fenecidos, Pérez Alonso, C 908-5.

36 «... Ítem, por quanto nosotros ovimos dado al dicho Diego de Soria, nuestro nieto, las diez cargas de pan de en censo e renta que teníamos en villa de Miro e un par de casas asy mismo en el dicho lugar, e después las trocamos con A. Muñoz de Castañeda a treynta cargas de pan de en censo quel tenía en Posada de Socastro e las hubo en la señora Doña Maria de Castañeda... mandamos, que por yquibalencia e fazer graçia al dicho Diego de Soria, nuestro nieto, quel aya e lebe las dichas treynta cargas de pan de en çenso que asi hubimos del dicho A. Muñoz de Castañeda por via de mayorazgo de la forma e manera e con las condiciones que en el dicho mayorazgo se contienen...» A.R.CH. Valldolid, Pleitos Civiles,, Fenecidos, Pérez Alonso, C 908-5.
} 
Un año antes de estas definitivas disposiciones, en 1506, Diego de Soria y su esposa, manifestaron su intención de dar la posesión de los tres mayorazgos constituidos a favor de sus nietos, reservándose el usufructo mientras viviesen ${ }^{37}$. Pedro de Soria es el único de los tres nietos que acompaña a sus abuelos, y asiste al acto de «toma de posesion» del mismo, que se hace siguiendo el protocolo y ritual acostumbrado ${ }^{38}$.

Inmediatamente después de la muerte de su abuelo, los jóvenes Soria, Diego y Pedro, quizá inseguros, se apresuraron a solicitar la expedición, de forma independiente, de algunas cláusulas del mayorazgo que a su favor éste había instituido. A la vez, también solicitaron la confirmación de algunas rentas integradas en el mismo. Diego de Soria, el mozo, lo hará en Abril de $1508^{39}$, al igual que su primo $P^{P e d r o}{ }^{40}$, aunque éste continuó solicitando a lo largo de los años 1.509, 1.511, diferentes confirmaciones. Todas afectaban a mrs. situados en diversas rentas ${ }^{41}$ integradas en su mayorazgo, que se alteraría por entonces al redimirse algunos maravedíes de juros, que pronto se reinvirtieron ${ }^{42}$.

\section{El principio del fin. ¿Una decisión política equivocada?}

Los tres flamantes mayorazgos estaban dispuestos para su propia andadura personal, y asociados emprendieron sus primeros negocios de comercialización de lana ${ }^{43}$. Juntos adquirieron en una zona por ellos bien conocida, la Sierra de Molina,

${ }^{37}$ «... e agora por façerles bien e merced a los dichos sus nietos e a ellos en su vida les quiere dar la posesion de los dichos vienes que asy estan encorporados en los dichos mayorazgos con tanto que en sy e para sy los dichos Diego de Soria e Catalina de Maluenda, su muger, retengan el usufruto de todos los dichos vienes en que asy fazen los dichos mayorazgos por vida de los dichos Diego de Soria e Catalina de Maluenda, su muger...». A.R.CH. Valladolid, Pleitos Civiles, Fenecidos, Pérez Alonso, C 980-5.

38 «...Pedro de Soria, nieto de los suso dichos, el qual paresçio ante el dicho alcalde e le pedió que por quanto los dichos señores Diego de Soria e Catalina de Maluenda, sus señores e aguelos, por le fazer bien e merçed les fa fecho e dado los dichos mayorazgos que así el dicho alcalde tiene en sus manos, e que los dichos sus aguelos los goçen por muchos años e buenos e pedía al dicho allcalde que conforme al dicho pedimiento fecho por los dichos sus señores aguelos, le metan en la posesion de los dichos vienes e mayorazgos..." A.R.CH. Valldolid, Pleitos Civiles,, Fenecidos, Pérez Alonso, C 908-5.

${ }^{39}$ A.G.S. Contaduría de Mercedes, leg. 28, fol.48, 17 Abril 1.508. Afectaban a mrs. situados en las alcabalas de Burgos, 20.000 mrs. situados en las alcabalas del vino, 4.500 en las de la carne, 2.500 en las de haber de peso y 2.500 en las del vino de odres.

${ }^{40}$ A.G.S. Contaduría de Mercedes, leg. 101, fol. 12, 11 Mayo 1508. Se confirman otros $20.000 \mathrm{mrs}$. en las alcabalas de Burgos. $10.000 \mathrm{mrs}$. en la renta de la carne de Burgos, $5.000 \mathrm{mrs}$. en las alcabalas de Santa María del Campo y 5.000 en las de Presencio.

A.G.S. Contaduría de Mercedes, leg. 106, fol. 52, 1508, Mayo 11, la reina Doña Juana confirma otros $20.000 \mathrm{mrs}$. en las alcabalas de Burgos. A la vez, en doc. Diferentes, $6.500 \mathrm{mrs}$. en las alcabalas de Mazuelo, A.G.S. Contaduría de Mercedes, leg. 101, fol.11 y 3000 mrs. en las de Olmillos, A.G.S. Contaduría de Mercedes, leg. 101, fol. 13.

${ }^{41}$ En 1.509, Noviembre 2, Valladolid, $7.250 \mathrm{mrs}$. situados en las alcabalas y tercias de la merindad de Castrogeriz y Villadiego, A.G.S. Contaduría de Mercedes, leg. 106, fol. 40; 16.000 mrs. situados en tercias de lugares del obispado de Segovia,, A.G.S. Contaduría de Mercedes, leg. 106, fol. 76; 13.433 mrs. en las alcabalas de Sevilla, A.G.S. Contaduría de Mercedes, leg. 106, fol. 77, más otros 5.000 mrs. situados también las rentas de esa ciudad, A.G.S. Contaduría de Mercedes, leg. 106, fol. 78.

${ }^{42} \mathrm{Se}$ adquirieron dos nuevos juros en compensación de los redimidos. A.G.S. Contaduría de Mercedes, leg. 106, fol. 32.

${ }^{43}$ Solía ser el primer negocio a emprender por parte de los burgaleses, ya que probablemente iba a ser el más importante en cuando a dedicación y también, porque se consideraba el más sencillo, solía 
importantes partidas de lana. En un primer momento, todavía en vida de su abuelo, 250 sacas, y poco después de su muerte, en 1507, 700 sacas que inmediatamente van a comercializar utilizando sus propios símbolos y distintivos comerciales. En el primer caso, el joven Juan combinó los trabajos de «apartar y señalar» la lana efectuados para la compañía de su abuelo, con los que efectuó para su primo y hermano. Pero para la adquisición de las 700 sacas, el joven Soria ya no fue a la sierra y se encargó de entregar a Lope de Orduña, criado de su primo Diego de Soria, el mozo, 3.000 ducados que le permitirían zanjar la operación, que requirió, no obstante, 500 ducados más que los jóvenes tomaron prestados de Jerónimo de Castro ${ }^{44}$.

El dominio y control de este negocio lanero resultaba imprescindible. Detrás vendrían otros: comercialización de otras materias primas, operaciones bancarias, conciertos de seguros... que, sin embargo, no llegaron. Son estas dos ocasiones, las únicas en las que, por ahora, hemos encontrado a los tres primos trabajar conjuntamente en negocios de envergadura, pues lentamente abandonaron el mundo del gran comercio internacional. ¿ Porqué este abandono?, ¿Acaso estos primeros negocios no dieron los resultados apetecidos?, ¿acaso no fueron capaces de hacer frente a los riesgos que las operaciones mercantiles y crediticias entrañaban?, ¿acaso las amargas diferencias familiares, los largos pleitos mantenidos por su padre y abuelo les llevó a rechazar el mundo que los había generado?, o ¿acaso los jóvenes Soria aspiraban a ocupaciones más prestigiosas como el servicio real?. Tampoco podemos olvidar otras poderosas razones que como una muerte prematura, una desastrosa actuación o error en situaciones políticas delicadas pudieron influir, o que simplemente el deseo de una vida cómoda y confortable sufragada por rentas cuantiosas se impusiese a la inseguridad, trabajo y dureza de los negocios. Tras seguir la pista de Diego y Pedro de Soria, vemos que muchos de estos factores estuvieron presentes.

Diego de Soria, el mozo, no fue el gran mercader que su abuelo había planeado. Efectuó sus primeros negocios laneros, pero nada más. Muy poco después, sin embargo, lo vamos a encontrar desempeñando otras actividades sumamente ansiadas y anheladas por un mercader del momento y que sólo unos pocos privilegiados alcanzarían: el servicio real. Su acercamiento a la persona real se vio favorecido por las influencias de su nuevo círculo familiar, el de su esposa Catalina de Salinas ${ }^{45}$. Este matrimonio concertado bajo los cánones de la endogamia grupal -la joven era la hija mayor de Juan Alonso de Salinas, amigo personal de Diego

evolucionar sin contratiempos y porque resultaba a los ojos de los burgaleses rentable y seguro. Ver mi trabajo «La formación y educación del mercader», XVI Semana de Estudios Medievales, Nájera, actas en prensa, y «Negocios laneros: Iniciación de una carrera comercial», en Actas de las I Jornadas sobre Minería y Tecnología en la Edad Media Peninsular, León, 1995, pag. 645.

44 «Negocios laneros... pág. 645

${ }^{45}$ En el documento sobre «Origen, sucesión, limpieza y nobleza de Diego de Soria, se nos relata el matrimonio de los descendientes del mercader. Además del matrimonio de Diego se emparentará con la familia Mota con el de una de sus hermanas. Catalina de Lerma, contrae matrimonio con con García Ruiz de la Mota, hermana del mercader. R. A H. Colecc. Salazar y Castro, C-25, fol. 101 - 107. 
de Soria y uno de los más acaudalados mercaderes de su tiempo ${ }^{46}$, también permitió al joven entrar en la influencia del nuevo soberano, ya que Catalina era sobrina del poderoso obispo Mota, uno de los favoritos del monarca. Así, en Diciembre de 1511 fue nombrado contino de su majestad con un sueldo anual de 40.000 mrs. anuales, y siete años después, el 20 de marzo de 1518, una nueva merced, más imprecisa, le asigna 50.000 mrs. hasta que se le prevea de algún oficio, cargo o prebenda; en 1521, una nueva gracia real le asignará otra merced de 100.000 mrs. de juro con carácter vitalicio, recordando en esta ocasión, los servicios especiales prestados en las Cortes de Valladolid de $1518^{47}$. Un año después Diego de Soria, el «mozo», moría ${ }^{48}$, perpetuándose su memoria en su hijo primogénito, Diego de Soria Lerma, de 16 años quien encabezaba la lista de nueve pequeños más ${ }^{49}$. Muchos, demasiados herederos para un patrimonio aminorado, que no había seguido creciendo al mismo ritmo que en años anteriores, y que, además, había sufrido un serio quebranto durante el movimiento de las Comunidades de Castilla, pues la intervención de la familia en éste supondría un duro golpe para la fortuna familiar; parte de la ruina de Diego de Soria, el «mozo», se labró en los disturbios y desórdenes que este importante movimiento político ${ }^{50}$ acarreó.

Cuando Catalina de Salinas, ya viuda, solicita de Carlos I una merced de $100.000 \mathrm{mrs}$. —creemos que puede tratarse del disfrute de la que se la había concedido a su esposo con carácter vitalicio-, dice necesitarla para poder vivir y mantener a su numerosa prole. Ella alega entonces la pérdida de su hacienda como consecuencia de la guerra, y se presenta desvalida y empobrecida. Sus propie-

${ }^{46}$ Era capaz de mover en el campo comercial 10.000 - 12.000.000 de mrs., poseía lavaderos propios en los que empaquetaba más de 600 sacas anuales de su propiedad, vivía en Burgos, en el barrio Huerto del Rey, en unas casas de las mejores de la ciudad y poseía en el lugar de Aguilar de la Bureba propiedades rústicas envidiadas por algunos de sus contemporáneos más que su tráfico comercial. Ver mi trabajo, «Acerca de la riqueza de los mercaderes burgaleses. Aproximación a su nivel de vida», En la España Medieval, 16,1993, pp. 100, 106 y 107.

47 Todas estar mercedes se reseñan en el documento sobre «Origen, sucesión, limpieza y nobleza de Diego de Soria citado anteriormente.

${ }^{48}$ Dudamos sobre la fecha de su muerte. El documento de limpieza de sangre aludido, dice que tuvo lugar en 1522. Sin embargo, C. MATHERS, que en principio también toma esa fecha la cuestiona poco después ya que los libros de actas municipales apuntan como fecha de muerte el 11 de junio de 1523, y añade además que el 7 de Mayo de 1523 él tuvo que comparecer personalmente en una sesión del concejo burgalés y jurar que el servicio votado a favor del emperador en las recientes Cortes, no había sido incondicional, MATHERS,C. «Dr. Martín de Velasco Soria, Royal Counciller». Agradezco a esta investigadora el envio del manuscrito de este trabajo que desconozco si ya ha sido objeto de publicación. En el mismo señala la influencia del obispo Mota como causa del acercamiento de la familia a la persona del monarca y a su favor.

${ }^{49}$ La inagotable fertilidad de Catalina no le impidió sobrevivir a su esposo en más de 20 años. De los 10 hijos de la pareja, siete fueron varones: Diego, Pedro, Juan, Martín, Bernardino, Jerónimo y Francisco, y tres hembras: Catalina, Francisca y Beatriz. R. A H. Colecc. Salazar y Castro, C-25, fol. $101-107$.

${ }_{50}$ Algunos títulos sobre este movimiento pueden ser: MARAVALL, J.A. Las Comunidades de CastiIla. Una primera revolución moderna, Madrid, 1963; GUTIERREZ NIETO, J.I. Las comunidades como movimiento antiseñorial, Barcelona, 1973; PÉREZ, J. La revolución de las comunidades en Castilla (1520 1521), Madrid, 1979; HALICZER, J. Los comuneros de Castilla: la forja de una revolución, Valladolid, 1987; SÁNCHEZ LEÓN, P. Absolutismo y comunidad. Los orígenes sociales de la guerra de las comunidades de Castilla, Madrid, 1998; DIAGO HERNANDO, M. Le comunidades di Castiglia, 1520-21: una rivolta urbana contro la monarchia degli Asburgo, Milano, 2001 y PÉREZ, J. Los comuneros, Madrid, 2001. 
dades habían sido expoliadas y sus casas destruidas durante los levantamientos, ya que los burgaleses parecían no perdonar que Diego de Soria, como representante de la ciudad en las Cortes de 1518 hubiese votado el servicio al emperador, y se hubiese mostrado proclive al mismo. Le acusaban, además, de buscar sus propios intereses y olvidarse del bien público. De hecho, en los últimos días de su vida tuvo que presentarse ante el concejo burgalés y dar explicaciones sobre su conducta y sobre su comportamiento en las Cortes, jurando ante sus convecinos que su voto favorable al emperador no había sido incondicional ${ }^{51}$. Podríamos decir, que Diego de Soria, había caído en desgracia.

El golpe dado a su persona y a su familia, lo podemos presentar como el resultado de un claro conflicto de intereses entre la oligarquía local y el común de la ciudad en su lucha por el poder, significando, a nivel particular, lo que el movimiento comunero significó para el conjunto del reino a juicio de $\mathrm{M}^{\mathrm{a}}$ Isabel del $\mathrm{Va}^{52}$. Diego de Soria constituyó en Burgos en torno a 1520 una víctima fácil, útil e ideal para ambos grupos y como tal, fue «sacrificada».

Su condición de procurador en las Cortes de 1517, que tantas expectativas personales abría suscitado por la ocasión que se le brindaba, actuaría ahora en su contra. Ambos grupos, notables y común, aprovecharon esa circunstancia para hacerle una misma y grave acusación: haber actuado en su propio beneficio. En lo que se consideraba un claro abuso de poder se habría alejado de un interés colectivo y buscado exclusivamente el personal.

Cuando el regimiento le pide explicaciones sobre su actuación, la oligarquía que la integra, está ya bastante segura sobre su futuro. Sus intereses económicos vertidos en un comercio de exportación se habían garantizado. La prosperidad parecía asegurada y con ella continuaría su situación de privilegio en la ciudad. No les interesaba, pues, continuar las veleidades «revolucionarias»; la moderación debía imponerse. Sin embargo, el descontento continuaba, era real. En gran parte, ellos mismos lo habían alentado, pero como en todo momento de tensión, cuando ésta estalla, resulta muy difícil encauzarla y apaciguar los ánimos. Burgos esta ardiendo, dirá el mercader Francisco de Mazuelo ${ }^{53}$, a la vez que expone las dificultades para hacer entrar en razón a un populacho apasionado, sobreexcitado por la propaganda de los comuneros que enficionan el aire ... Pero todavía se podía hacer entrar en razón a los exaltados. Se podía aprovechar el momento, actuando con rapidez y no esperando a que la situación se deteriorase más. Negociar, convencer, adular los sentimientos de la población, satisfaciendo parte de sus exigencias, aunque ello supusiese el sacrificio de alguno de sus propias filas. Se podía proceder contra los procuradores en las Cortes pasadas exigiendo su castigo.

51 Ver nota 53.

52 VAL VALDIVIESO, $\mathrm{M}^{\circ} \mathrm{I}$. «La revolución comunera como punto de llegada de las luchas por el poder en las ciudades castellanas del siglo XV», Scripta. Estudios en Homenaje a Elida García García, Oviedo, 1998, pp. $617-33$.

${ }^{53}$ PÉREZ,J. La Revolución de las Comunidades..., Madrid, 1979, pág. 205 
Así se daría gusto a ese populacho, descontento y díscolo, permitiéndosele algún "capricho». Diego de Soria podía ser una «buena víctima», pues reunía en su persona diferentes condiciones para ser inmolado. Era regidor, era rico, había sido procurador, no en La Coruña pero sí en Valladolid, y además, estaba emparentado con el obispo Mota, hombre de entera confianza del monarca, inspirador del discurso que él mismo había pronunciado ante las Cortes $^{54}$. Al ser regidor, pertenecía a la oligarquía urbana que se sentía amenazada por el cariz que iban tomando los acontecimientos. Era una persona del grupo dominante, pero que ese mismo grupo consideraba que podía ser su víctima, y como tal lo ofrece a la crispación del común, que ellos mismos habían alentado. Los notables burgaleses al permitir que las iras populares se cerniesen sobre uno de ellos, simplemente estaban reaccionando en su autodefensa. Nadie les acusaría de proteger sus intereses de grupo si reconocían la culpabilidad de uno de ellos, que era, además, rico y poderoso. Tengamos en cuenta que el odio y envidia hacia los más ricos nos lo presenta el cronista Maldonado como móvil de los acontecimientos y justificación de los saqueos, «... todos los que son ensalzados mas de lo regular por un repentino soplo de fortuna, excitan la envidia de sus conciudadanos y vecinos...» 55 «... se trataba de robar a los más ricos...» ${ }^{56}$; García de la Mota y Diego de Soria lo eran, «... se fue deslizando la plebe, furiosa, unos a casa de Mota, que hervía de ladrones, y con un incendio se libraba de otro; otros a casa de Diego de Soria, que había sido procurador por Burgos en las anteriores Cortes de Valladolid y que se le imputaba haber impuesto sus intereses a la conveniencia y mandatos públicos... „57.

Ambos grupos, oligarquía y común, vierten hacia la persona del regidor una misma acusación, "....haber antepuesto sus intereses a la conveniencia y mandatos públicos...", haber aprovechado su estancia en la corte representando a la ciudad para defender exclusivamente sus intereses personales, intereses que quizá fuesen coincidentes con los de otros notables, pero que, sin embargo, éstos disimulan para intensificar la culpabilidad de un tercero $0^{58}$. En un ambiente de malestar, éste se incrementa notablemente con rumores, bulos incontrolados o hábilmente

${ }^{54}$ La importancia del discurso la resalta PÉREZ, J. En su La Revolución de las Comunidades ... pp. 148-50. También se recoge esta importancia en el comentario a la Crónica de Juan de Maldonado. La Revolución comunera. El movimiento de España, o sea historia de la revolución conocida con el nombre de las comunidades de Castilla, ed. FERNÁNDEZ VARGAS, V., Madrid, 1975, pág. 92, al señalar que Menéndez Pidal vio en el mismo la primera expresión de la idea imperial de Carlos $\mathrm{V}$.

${ }^{55}$ Crónica de Juan de Maldonado... pág. 93. Explicación que da el cronista cuando narra el asalto a la casa de García de la Mota, «... además de haber sido procurador en La Coruña, era también aborrecido de los populares por otros motivos, y aunque no hubiese otro, todos los que son ensalzados mas de lo regular por un repentino soplo de fortuna, excitan la envidia de sus conciudadanos y vecinos...»

${ }^{56}$ Crónica de Juan de Maldonado...pág. 108

57 Crónica de Juan de Maldonado... pág. 94.

${ }^{58} \mathrm{La}$ acusación de preocuparse exclusivamente por sus intereses particulares fue habitual en el movimiento. Los grandes del reino también fueron acusados por los frailes comuneros de atender sólo a sus intereses particulares, ver, LÓPEZ PITA, P. «Nobleza y monarquía en el tránsito a la Edad Moderna. Títulos y Grandes en el en el movimiento comunero», en Títulos, Grandes del Reino y Grandeza en la Sociedad Política. Fundamentos en la Castilla Medieval,163-273, Madrid, 2006, Mª C. QUINTANILLA RASO (dir.). 
controlados por el poder... Poco importaba ahora que esos propios objetivos personales fuesen los mismos que los de otros muchos mercaderes - regidores. Éstos, como grupo, cedían ante el común, ofreciéndoles como víctima a uno de ellos a quien se le podía mirar con recelo, dado su parentesco con el obispo Mota, a quien en 1520, 1521 , sólo se veía en Burgos como un hombre de confianza de un monarca cuestionado, que junto a los consejeros extranjeros del mismo, atraía las iras de la multitud. Había sido, además, el autor del discurso de apertura de las Cortes de La Coruña arengando a los asistentes a aceptar los subsidios en pro de un política imperial presentada «falsamente» como sumamente interesante para el reino ${ }^{59}$. Era pues, responsable directo del subsidio; su parentesco resultaba claramente perjudicial, y añadía peligrosidad a su condición de procurador y rico. Mientras la vivienda de García de la Mota, mercader y hermano del obispo, fue tomada al asalto y expoliada, la de Juan Pedro de Cartagena, también procurador en las mismas Cortes de la Coruña se respetó. No ocurrió lo mismo con la de Diego de Soria, no presente en La Coruña, aunque sí en Valladolid, que fue igualmente asaltada ${ }^{60}$.

El compromiso con la Corona en esos momentos le había costado caro. Además de unas pérdidas económicas en sus propiedades burgalesas, difíciles de evaluar - pero posiblemente exageradas por su viuda - había perdido su prestigio, su buen nombre entre sus conciudadanos, su confianza, lo que era muy importante para un mercader. Recuperarla le iba a resultar difícil, aunque el joven Soria lo intentase disculpándose ante el ayuntamiento burgalés. Pero no fue suficiente. Su honor realmente se había comprometido.

¿Acaso el apoyo a la Corona podía compensarle?. En esta ocasión parece que no, pues cuando el monarca realmente consolidó su poder, ya era tarde para el mercader; había muerto.

Apostar por la recién implantada monarquía podía suponer ventajas ${ }^{61}$. Además, el joven monarca flamenco, podía favorecer sus intereses no sólo en la península, sino también en su país de origen, por lo que la esperanza de compensaciones por

\footnotetext{
59 Ver nota 59.

${ }^{60}$ García de la Mota, mercader y hermano del obispo, también atraía el odio de la multitud ... Garcia de la Mota había caído entonces en gran odio de la plebe, no sólo por haber sido procurador en las Cortes de la Coruña, sino también por ser hermano de Pedro Mota, obispo de Palencia, que a la sasón gozaba de gran favor de don Carlos ...». Su casa burgalesa fue expoliada «... se arrojaron sobre la casa de Mota; alhajas de todas clases de que estaba llenísima la casa, parte las robaron, parte las quemaron en frente de la puerta, en medio de la plaza, y si su esposa e hijos no se hubiesen salido ocultamente por una puerta excusada, y se hubiesen refugiado en casa de Osorio, hubieran sido arrojados y perecido en la misma hoguera con las alfombras, colgaduras y paños ..." Crónica de Juan de Maldonado, 92-3. Seguimos sus explicaciones con respecto a Cartagena, «... se hallaba entonces en la ciudad Juan Pedro de Cartagena, otro de los procuradores; pero cuanto se le juzgaba más pobre porque aún vivía con su madre y menos favor para con el rey e empleados palaciegos, tanto menos le aborrecía el pueblo...», 93-4. Con respecto al asalto de la casa de Diego de Soria, ver, nota 62.

${ }^{61}$ Las expectativas nobiliarias y sus diferentes posturas en LÓPEZ PITA, P. «Nobleza y monarquía en el tránsito a la Edad Moderna. Títulos y Grandes en el en el movimiento comunero», en Títulos, Grandes del Reino y Grandeza en la Sociedad Política. Fundamentos en la Castilla Medieval,163-273, Madrid, 2006, Ma C. QUINTANILLA RASO (dir.).
} 
servicios prestados se agrandaba. En las Cortes de Valladolid se había presentado ante el procurador burgalés una excelente oportunidad para demostrar a la Corona su actitud y apoyo. Su voto era decisivo, y no pasaría inadvertido ni de qué ciudad ni de qué persona procedía. Quizá el joven Soria recordase como años atrás, su abuelo, Diego de Soria, había sabido conjugar sus propios intereses personales con los de su ciudad y con los de la Corona poniéndose abiertamente a su servicio, Él había acertado y probablemente se lo recordase a su nieto en diferentes momentos aconsejándole que el favor real era importante para los grandes negocios. Pero la situación de guerra civil que condujo al trono a Isabel y Fernando no era comparable con la que vivía el país y la ciudad burgalesa en los albores del siglo XVI, ya que en esta ocasión, parece que los intereses de la Corona no coincidían con los de la ciudad de Burgos ni con los de su procurador Diego de Soria, o por lo menos, los burgaleses no lo entendieron así. No comprendieron la actitud de Soria, o comprendiéndola demasiado bien, dedujeron que claramente respondía a sus intereses y expectativas particulares, no al «bien común». Y así se lo reprocharon cuando le exigieron explicaciones ante el ayuntamiento burgalés. Aunque pidió perdón, se disculpó públicamente, no pudo recuperar su buen nombre y la confianza de sus conciudadanos. Le faltó tiempo, ya que poco después de su justificación ante el concejo, muere. Había cometido un grave error político.

Tras su muerte, su hijo primogénito, un nuevo Diego de Soria que adopta también el apellido Lerma, Diego de Soria Lerma, accede al regimiento. A ello no se opone el grupo, lo acepta. Su edad, 16 años, su condición de huérfano y su fragmentada hacienda, lo señalan como presumiblemente manejable. No constituía un obstáculo para la oligarquía local ni mucho menos para sus intereses. El flamante nuevo «heredero» todavía pudo mantener su estatus sensiblemente deteriorado. Las rentas del mayorazgo eran significativas y así se lo permitían. Contrajo un respetable matrimonio con Inés de Sanzoles, hija del mercader Alonso de Sonzoles y disfrutó en Burgos de una cómoda posición. Pero no les ocurrió lo mismo a sus hermanos, quienes sufrieron de forma más aguda la temprana muerte de su progenitor y la merma de su hacienda sometida a múltiples particiones. El camino religioso emprendido por las mujeres aliviaba la situación, pero no resultó suficiente, por lo que los varones se vieron obligados a buscar fortuna en otros lugares y en otros modos de vida. Abalados por una buena formación, despuntarían en el mundo de las letras y en la guerra. Especial mención requieren Martín de Soria Velasco o Martín de Velasco Soria, el Dr. Velasco, quien llegó a ser miembro del Real Consejo de Castilla ${ }^{62}$, calificándosele en ocasiones de gran privado de Felipe $\|^{63}$, y su hermano fray Bernardino de Salinas, maestro en Teología, fraile je-

62 Ver nota 54.

${ }^{63}$ En el documento de limpieza de sangre, tantas veces mencionado, R.A.H. Col. Salazar y Castro, C -25 , fol. $101-7$ ya mencionado, falta una hoja, precisamente la que debía proporcionarnos información sobre su persona. Pero en otro documento similar sobre la sucesión de Diego de Soria y Catalina de Maluenda, elaborado a raíz de las dudas que surgieron sobre la exclusión femenina de los mayorazgos por 
rónimo, quien asistió en Yuste al emperador, entreteniéndole con lecturas piadosas $^{64}$.

El servicio de las armas lo siguieron Pedro, Juan Alonso y Jerónimo. Pedro, a quien siempre se le denomina Pedro de Lerma ${ }^{65}$; el capitán Lerma, se dirigió a América en busca de gloria, fama y aventuras ${ }^{66}$. Allí participó activamente en la conquista de una de las provincias del Perú, donde se estableció temporalmente y tuvo un hijo natural, llamado como él Pedro de Lerma. Murió al servicio del emperador $^{67}$. Sus hermanos prefirieron, sin embargo, destinos más clásicos: Italia y Flandes. Juan Alonso de Salinas sirvió al emperador en las guerras de Italia donde encontró la muerte, y Jerónimo de Soria y Salinas, capitán, guerreó también en Italia y Flandes, donde moriría. Llegó a ser castellano del castillo de Gante. Bernardino y Francisco prefirieron entrar en religión ${ }^{68}$.

Habíamos visto también como Diego de Soria había favorecido a otros dos de sus nietos varones, los hijos de Leonor, con otros dos importantes mayorazgos: el de Mazuelo y el de Arroyo, de los que disfrutarían Pedro Pardo y Juan Pardo Soria respectivamente, y cómo estos jóvenes habían emprendido junto con su primo negocios laneros.

La vida de estos dos mayorazgos no fue larga. Se extinguieron pronto al carecer de herederos. En el caso de sus primos, muy prolíficos, vimos que las innumerables particiones patrimoniales, aunque no afectaron al mayorazgo, habían acabado por arruinar un maltrecho patrimonio familiar. Era ése un peligro a correr. Pero también sabemos, que reducir el número de herederos podría entrañar otro, no menos preocupante: el fin y extinción. Y eso fue lo que ocurrió en la rama familiar que ahora nos ocupa..Pedro de Soria, primogénito de Leonor de Soria y Alonso Pardo, que había contraído matrimonio con Juana Orense, tuvo dos hijos:

ellos fundado, R.A.H. Col. Salazar y Castro, C - 25, fol. 93-99, nos dice «... Doctor Martín de Soria Velasco, collegial de Oviedo y de los consejos de estado y cámara del rey don Phelipe, segundo y su gran pribado...".

${ }^{64}$ El doc, de limpieza de sangre así nos lo explica «...Fray Bernardino de Salinas, maestro en Santa Teología, fraile de la orden de San Jerónimo, que asistió en Yuste, monasterio de su horden con el emperador Carlos quinto hasta que murió, leyendo teología y otras cosas en santos ejercicios su majestad se ocupaba y entretenía, y por ser tan eminente y gran letrado le eligió...» C. MATHERS en su trabajo sobre Martín de Soria, señala que se había licenciado por la Universidad de París.

${ }^{65}$ Fijémonos en la alternancia de apellidos (paterno - materno)de todos los hermanos: Pedro de Lerma, Juan Alonso de Salinas, Jerónimo de Soria y Salinas, Martín de Soria Velasco, Bernardino de Salinas, Francisco de Soria, y el mayorazgo Diego de Soria, R.A.H. Col. Salazar y Castro, C - 25, fol. 107. Pedro de Lerma adopta el apellido de su abuelo.

${ }^{66}$ Este camino fue también elegido por otros muchos hijos de mercaderes burgaleses. Véase por ejemplo el trabajo de MATHERS, C. Y SCHWALLER, J.F. « A trans - atlantic Hispanic family: The Mota clan of Burgos and México city», Sixteenth Century Journal, XXI, 3, 1990, 411-36.

${ }^{67}$ De Pedro de Lerma nos dice el documento de limpieza de sangre «... que pasó a las Indias en servicio del emperador Carlos quinto de gloriosa memoria, siendo capitán de infantería española, y en la conquista de cierta provincia del Perú fue capitán general, haciendo en esta y otras ocasiones tan hazañosos hechos y notables servicios como refieren algunas de as historias de las Indias, a donde hubo un hijo natural, Ilamado como él Pedro de Lerma...». R.A.H. Col. Salazar y Castro, C - 25, fol. $101-7$.

${ }^{68}$ R.A.H. Col. Salazar y Castro, C - 25, fol. $101-7$. 
Francisco Pardo y Juan Bautista de Soria Pardo. Ambos murieron sin sucesión, por lo que se mayorazgo se incorporó al de su primo Juan Pardo Soria ${ }^{69}$.

Pedro Pardo fue de los tres nietos beneficiados con mayorazgos el que había continuado durante más tiempo involucrado en la práctica mercantil. Por lo menos, lo encontramos explorando el comercio americano y realizando importantes préstamos a la Corona. Tuvo parte en el cargamento de oro y plata que en cinco naves llegaba a Sevilla en 1524 y de los que le correspondían 1.33342.236 mrs. que le granjearon ciertos mrs. de juro en las en las alcabalas del aceite de Sevilla tras el embargo real decretado ${ }^{70}$. Es muy probable que éste fuese el primer embargo de metales preciosos y perlas provenientes de las Indias decretado por la Corona para hacer frente a sus necesidades.

Tras ésta no tenemos más noticias de nuevas aventuras comerciales. Quizá no resultó satisfactoria, o su final, en principio imprevisto, le animó a refugiarse en su condición de rico propietario agrícola en Mazuelo y en el lustre que podía proporcionarle su condición de hijosdalgo, condición que además, muy pronto se iba a cuestionar. Antes de llegar a mitad de siglo, el concejo de Mazuelo lo hará y prendará parte de sus bienes ${ }^{71}$. Poco después, tras la oportuna reclamación y ante la exhibición del correspondiente privilegio ${ }^{72}$, Pedro de Soria consigue la res-

${ }^{69}$ R.A.H. Col. Salazar y Castro, C - 25, fol. $101-7$. Se señala también la fecha de su muerte. Pedro de Soria falleció el 15 de Diciembre de 1552; su esposa Juana de Orense el 12 de Abril de 1572 y su hijo Juan Bautista Soria el 20 de marzo de 1587. Yacen todos en la iglesia de San Gil.

${ }^{70}$ AGS, Contaduría de Mercedes, leg. 101, fol. 84, confirmación de los mrs. de juro situados en la alcabala del aceite de Sevilla. Este documento contiene un albalá del emperador en que hace referencia a sus elevados gastos y como para hacer frente a los mismos, siguiendo la política de sus abuelos «... se acordaron socorrer presto del oro e perlas de mercaderes e personas principales que tuvieron las cinco naves que vinieron de las Indias el mes de Setiembre del año pasado de 1522, lo qual reíbio en nuestro nombre Juan de Aranda, nuestro fator en la casa de contratación de las Indias que reside en la çibdad de Sevilla»... A cambio se decretó que se pagará lo tomado al precio de $14.000 \mathrm{mrs}$. el millar. Los mrs. de juro se situarían donde el interesado quisiere con algunas excepciones: ciudad de Segovia, Ávila, Medina del Campo, Aranda, Sepúlveda y Madrigal. La Corona, como era habitual se reserva el derecho a levantar el juro por el preció que se constituyó, con la condición de no levantar menos de la mitad de una sóla vez. Pedro de Soria muestra un recibí de Juan de Aranda y solicita, por tanto, la confirmación correspondiente. Recibí de 1.342.236 mrs. a los que le corresponden $95.874 \mathrm{mrs}$. de juro «... los quales resçibi del oro e perlas que vinieron de las yndias en las çinco naves que de ella venyeron en el mes de Setiembre del año pasado de 1522...»El recibí tiene fecha de 30 junio 1522. Soria los situó en la alcabala del aceite de Sevilla y los empezaría a cobrar el año 1526.

${ }^{71}$ A. R. Ch. Valladolid, Sala de Hijosdalgo, 746 - 7. 1.542, Valladolid, junio 6, Carta del emperador al concejo de Mazuela en la que relata una demanda de Pedro de Soria contra el citado concejo. De ella se desprende cómo le cuestionaron su condición de hijosdalgo y la ejecución de prendas «...quel dicho su parte vos tenía puesta demanda sobre que seyendo el hombre hijodalgo notorio, vosotros le prendabades por pecho de pecheros por la hazienda que tenia en esa dicha villa e maliciosamente le abiades prendado e tomado prendas por los pechos pasados de veinte años atrás e le abiades tomado muy grandes prendas...

72 El procurador de Pedro de Soria tendría que insistir y mostrar el privilegio «... tiene privillegio por lo mandado de los Reyes Católicos Don Fernando e Doña Isabel de gloriosa memoria, sacado e guardado, por el cual el dicho mi parte es hombre hijosdalgo de solar conocido de devengar 500 sueldos según fuero de España como nieto legítimo que es de Diego de Soria, defunto, regidor e vecino que fue de la çibdad de Burgos, hijo legitimo de Leonor, hija del dicho Diego de Soria e de Alonso Pardo, su marido, como el tenero del dicho privilegio pareçe, del qual hago presentación... A. R. Ch. Valladolid, Sala de Hijosdalgo, $746-7$ 
titución de los bienes prendados ${ }^{73}$, pero ya había sufrido un penoso ultraje y humillación.

Acaso el concejo de Mazuelo aprovechaba la mayor debilidad del nuevo propietario para resarcirse de las humillaciones a las que el gran mercader les había sometido. Probablemente antiguos rencores estaban en juego cuando emprendieron tal reclamación que claramente iban a perder. Por lo menos, así lo quiere dejar ver Pedro de Soria cuando explica que lo hicieron por le destruyr ${ }^{74}$. También podían emular al concejo de Pampliega, que unos años antes, en 1530, le discutía al mismo Pedro de Soria la entrega de un censo de 10 cargas de pan que se habían comprometido a entregar a su abuelo y que él había heredado ${ }^{75}$. No había razón aparente para hacerlo, simplemente, el concejo y vecinos de Pampliega se habían cansado de pagar y solicitaban la exhibición de los títulos que justificase tal censo, esgrimiendo que les resultaba especialmente gravoso, sobre todo el servicio de transporte que suponía la obligación de entregarlo en Mazuelo ${ }^{76}$. Tampoco era la primera queja. Incluso recién contraída la obligación, vecinos del lugar, alegaron que era un engano manifiesto y pretendieron inútilmente librarse de la misma ya que las cartas de venta existían y en ellas se reflejaban claramente las condiciones sin importar que el trato resultase desigual e injusto ${ }^{77}$. Jugando con una necesidad imperiosa, Diego de Soria, como cualquier otro poderoso, había conseguido censos especialmente ventajosos, haciendo creer a los vecinos de los pequeños lugares que los conciertan que actúan como auténticos benefactores de la

\footnotetext{
${ }^{73} 6$ octubre 1543. Se dicta sentencia a favor de Pedro de Soria , «...fallamos quel dicho Pedro de Soria probó bien y conplidamente su intención y demanda, damos e pronunciamos su intención por bien probada y el dicho procurador fiscal de sus majestades, conçejo e homes buenos de la dicha villa de Maçuela no probaron sus exebçiones ni defensiones ni su intención ni cosa alguna que les aproveche, damos e pronunciamos su intención por no probada, pronunciamos e declaramos el dicho Pedro de Soria ser fonbre hijodalgo de padre e abuelo conforme el pribillegio de hidalguia por su parte en el proçeso del dicho pleito presentado...» «... Tornen e restituyan e entreguen al dicho Pedro de Soria todas e qualesquier prendas e bienes que les ayan sido tomadas e embargadas por los dichos pechos...» A. R. Ch. Valladolid, Sala de Hijosdalgo, $746-7$.

${ }^{74}$ Cuando se trata de explicar las razones injustificadas de as prendas, sólo se puede esgrimir, que se las hicieron por le destruyr, A. R. Ch. Valladolid, Sala de Hijosdalgo, $746-7$

${ }^{75}$ A.R.CH. Valladolid, Esc. Pérez Alonso, leg. 908, exp. 5

${ }^{76}$ Vecinos de Pampliega manifestaban que no había razón para esa negativa. Así, Pedro de Villanquera explica cómo se había pagado sin contradicción durante mucho tiempo, pero que desde hacía tres años, lo cuestionaban "...de tres años aca poco mas o menos quel dicho concejo se a puesto en no se lo querer pagar diciendo que mostrase el título que tenia por do se lo avían de pagar..."_Juan Martínez de la Calzada nos dará la misma explicación «... que puede aver un año poco mas o menos quel dicho concejo de la villa de Pampliega se le puso en no se lo pagar..." Todos declaraban, además, haber visto las cartas censales . A:R.CH. Valladolid, Esc. Pérez Alonso, leg. 908, exp. 5. Pedro García, vecino de Pampliega, dirá que les oyó quejarse de esta obligación «...decían unos a otros, pese al diablo, no vasta pagar este pan de çenso, sino llevarlo a Maçuela...».

${ }^{77}$ A.R.CH. Valladolid, Esc. Pérez Alonso, leg. 908, exp. 5. Una de las cartas de censo tiene fecha de 2 de marzo de 1488, otra del 20 de marzo de 1489, una tercera del 23 de Febrero de 1490, y la cuarta del 24 de Febrero de 1490. Todas fueron firmadas en Pampliega. Se trataba de 10 cargas de pan, mitad trigo y mitad cebada, que debían entregarse en Mazuelo, por Santa María de Septiembre a costa del concejo de Pampliega y durante tres vidas, la de Diego de Soria, la de su esposa Catalina de Maluenda y la de su primer heredero, Después serían ellos quienes corriesen con los gastos de transporte.
} 
localidad ${ }^{78}$. Resultaba casi el único modo en que esos lugares podían disponer de algún dinero para costear ciertas empresas u obras que esos lugares necesitaban $^{79}$. Cincuenta años más tarde, no era más que un triste recuerdo.

El hermano de Pedro, Juan Pardo Soria, titular del mayorazgo de Arroyo, contrajo matrimonio con $\mathrm{D}^{\mathrm{a}}$ María Meléndez, hija de Nuño Meléndez, tesorero del monarca. Tuvieron tres hijos: Juan, Francisco y María. Juan heredó de su padre el mayorazgo de Arroyo y se benefició también con el de Mazuelo al morir sin sucesión su primo Juan de Soria. Contrajo matrimonio con Beatriz de Polanco, hija de Andrés de Polanco y Ana de Salamanca. Tuvieron solamente un hijo varón que murió siendo niño y algunas hijas ${ }^{80}$. Obsesionado por conseguir un heredero que perpetuase su apellido y heredase ambos mayorazgos, contrajo segundas nupcias con Isabel de Alvarado. Este matrimonio no tuvo descendencia ${ }^{81}$, por lo que se presentaba tortuosa la herencia de estos dos mayorazgos al ser excluidos del mismo, en principio, la línea femenina y recaer, por tanto, los tres mayorazgos en la persona de Diego de Lerma, hijo de Diego de Lerma y Magdalena de Castro $^{82}$. Los mayorazgos fundados por Diego de Soria y su esposa revertían aunque cinco generaciones más tarde, a los descendientes de Diego de Soria, el mozo, aquel que en su día el viejo mercader había querido primar. Pero en ese momento, cien años después, esa ventaja ya no tenía muchos sentido.

${ }^{78}$ A.R.CH. Valladolid, Esc. Pérez Alonso, leg. 908, exp. 5 Juan Recio, vecino de Mazuela, recuerda como algunos vecinos de Pampliega, Pedro Manrique, Pedro Morón, hablaban en Mazuela con el mercader, en su casa, estando también presentes vecinos de Mazuela y habían oído decir a Diego de Soria «... porque no azeys vosotros un censo como estos buenos omes hazen para faboresçer a su pueblo ...»

${ }^{79}$ A.R.CH. Valladolid, Esc. Pérez Alonso, leg. 908, exp. 5 Diego de Soria reclamaba el pago de unos mrs. que les había prestado para la construcción de una fuente «... que le pagasen ciertos maravedís quel conçejo de la villa de Maçuela le devían de la fechura de la fuente...».

${ }^{80}$ R.A.H. col. Salazar y Castro, C - 25, fol. 101- 107.

${ }^{81}$ R.A.H. col. Salazar y Castro, C -25 , fol. 93-99.

82 R.A.H. col. Salazar y Castro, $\mathrm{C}-25$, fol. 93-99. Es esta situación la que genera e citado documento que concluye «...esta es la subzesion de los dichos Diego de Soria y Catalina de Maluenda y de sus tres nietos en quienes fundaron los tres mayorazgos que se an dicho, y como consta de la escriptura de su fundación que vuestra merced ha visto excluye en la subzesion dellos hembra, en la qual mirado con alguna atención pareze tiene las dificultades que en este papel ban, y que muerto el dicho Juan pardo de Soria cuyos mayorazgos herda don Diego de Lerma, hijo de los dichos diego de Lerma y Magdalena de Castro, se les podría oponer la dicha Doña Catalina Pardo, su hija y el dicho Don Juan Gutierres, su marido, aun en lo que advierto al pie de cada dificultad no pareze tiene ninguna, mas por si llegado el caso quisieran balerse dellas, suplico a vuestra merced nos advierta de lo hemos de hazer al punto que esto llegue, y perdone vuestra merced este atrevimiento y trabajo porque con esta merced no tenemos que temer...». 